\title{
Going viral: riding the RNA wave to discovery
}

\author{
NILS G. WALTER \\ Single Molecule Analysis Group, Department of Chemistry, University of Michigan, Ann Arbor, Michigan 48109-1055, USA
}

I have a dream. I have been hooked on it ever since 25 years ago when I prepared for my German diploma exam by reading a chapter in Lubert Stryer's Biochemistry textbook about catalytic RNAs, or ribozymes. Around this time the journal RNA was born as a manifestation of a growing RNA field and society. My PhD mentor Manfred Eigen organized regular winter seminars in Klosters, Switzerland; hearing Tom Cech talk at one of them about the beauty of RNA catalysis underscored just how relevant his and Sid Altman's discovery of non-protein catalysts was, earning them the Nobel Prize in Chemistry just a few years earlier in 1989. I decided to become part of the discoveries in the RNA World since they would reveal from where we came through deciphering the Origin of Life; as well as make us appreciate our roots and each other through the interconnectedness embodied in the Tree of Life. Yet throughout my graduate and postdoctoral studies of ribozymes I would feel that a piece of the puzzle was missing. It seemed rather strange to think of the primordial RNA World as a place of ubiquitous RNA functions that entirely would be lost in translation. I dreamed-like probably many of us - that somehow there had to be more to life than passive, repository nucleic acids and busy protein doers. And it turns out there is, in a big way.

It is only a little over 60 years ago that Alfred Hershey and Martha Chase discovered that DNA represents the genetic material that stores all information necessary for life. A mere decade ago or so, the $\sim 3$ billion base pairs of our genome were first sequenced in their entirety through the human genome project, at a cost of $\sim \$ 1$ per base pair. The expectation for this breakthrough was that the identification of genetically encoded protein aberrations would realize a new era of personalized medical treatment for intractable human diseases such as cancer and Alzheimer's. Instead, it revealed the stunning truth that $<21,000$ protein-coding genes, only $\sim 5$-times the number of a bacterium, span just $\sim 1.2 \%$ of the human genome. As a result, the Encyclopedia Of DNA Elements (ENCODE) project was initiated as an international collaborative research effort to provide a comprehensive catalog of all functional elements within the human genome through unbiased, transcriptome-wide cov-

Corresponding author: nwalter@umich.edu

Article and publication date are at http://www.rnajournal.org/cgi/doi/10. 1261/rna.049403.114. Freely available online through the RNA Open Access option. erage by RNA deep-sequencing (RNA-seq). This work further revealed that while $75 \%$ or more of our genome is transcribed, the vast majority of these transcripts do not code for proteins but rather for "non-coding" RNAs (ncRNAs), many of which remain uncharacterized in terms of their structure and function. Currently, more than 80,000 unique ncRNAs have been identified in human cells alone. Clearly, for a long time we have underestimated the intricacies involved in human genome maintenance, processing, and regulation by neglecting a class of major players, the vast plethora of ncRNAs, referred to by John Mattick and colleagues as an "RNA machine." With the still expanding catalog in hand, now has come the time to resolve the legacy of the human genome project and understand the multitude of RNA functions inside the cell.

Ribozymes became an attractive type of RNA to study in the 1980s and beyond due to their promise to bring us closer to the Origin of Life, and their structural complexity combined with an easy-to-follow functional activity. The human genome project together with the modern RNA-seq approaches it inspired have since vastly expanded our RNA universe. One consequence of this explosion in particularly attractivesince biologically profound, yet still enigmatic-target repertoire for scientific study has been a massive influx of researchers into the RNA field; many cell biologists, geneticists, biochemists, plant biologists, etc. discovered that RNA impacts their preferred biological pathway in such a profound way that it could no longer be ignored. The resulting combination of more study targets and more researchers has led to RNA going "viral" - just as in a viral epidemic, the "replicating" new RNA targets "infect" more and more researchers, leading to non-linear, exponential growth of the field. Even the timeline of Nobel Prizes suggests such an accelerationstarting from the 1989 Nobel Prize in Chemistry to Cech and Altman, through the 1993 Nobel Prize in Physiology or Medicine to Richard Roberts and Phil Sharp for split genes (i.e., pre-mRNA splicing), to the 2006 Nobel Prize in Physiology or Medicine to Andrew Fire and Craig Mello for RNA interference, and the pair of awards in 2009, the Nobel Prize in Chemistry to Venki Ramakrishnan, Tom Steitz, and Ada Yonath for functionally relevant crystal structures of

(C) 2015 Walter This article, published in RNA, is available under a Creative Commons License (Attribution-NonCommercial 4.0 International), as described at http://creativecommons.org/licenses/by-nc/4.0/. 
the ribosome and the Nobel Prize in Physiology or Medicine to Elizabeth Blackburn, Carol Greider, and Jack Szostak for studies of the RNA-guided protein enzyme telomerase.

Traditionally, the RNA field has been very welcoming to new faces, and the current transformative period is no different. However, the viral transformation of an entire field also means that we have to think strategically about where we can contribute the most exciting science among the many possible lines of inquiry. Such healthy soul searching is evident in the session topics at the annual RNA Society meetings that have evolved particularly over the past decade, adding "riboswitches" to "ribozymes," increasingly invoking RNA-based and RNA-targeting regulation, highlighting RNA-programmable eukaryotic genome editing through the CRISPR/ Cas9 technology, and more generally examining the application potential of RNA technologies and therapies.

In the author's view, the most profound insight, however, arises from the notion of "RNA interconnections" and the resulting non-linear, emergent properties of RNA pathways. For example, as Melissa Moore and Nick Proudfoot have noted, pre-mRNA processing reaches back to transcription through coordinated timing and reaches ahead to translation through sharing of protein marks. In addition, evidence is accumulating that target competition through the crosstalk between diverse competing endogenous RNAs (ceRNAs), including mRNAs and ncRNAs such as long ncRNAs, pseudogenes and circular RNAs that act as "sponges," profoundly influences microRNA-mediated gene regulatory networks. Finally, many RNA-processing proteins may have passive binding sites on RNAs that they do not process, leading to their sequestration away from actual target RNAs. Such complex networks of interactions go beyond the seemingly linear enzyme cascades we are used to seeing in textbooks on met- abolic pathways, and are not easy for us to follow due to our innate tendency to divide complex interconnected networks into linear cause-and-effect relationships. However, they do closely mimic the way the scientific endeavor itself functions, with scientists forming transient collaborations seemingly at random based on physical proximity, chance encounters, and shared interests ("affinities"); the social network a scientist builds profoundly influences their scientific trajectory, leading to many "random walks" and serendipitous discoveries - the revelations of RNA interference through studies of nematode worms and of CRISPR/Cas9 through studies of bacterial genomes come to mind. This mimicry—or fractal self-similarity over a length scale from molecules to people -implies that the scientific endeavor is well matched to the challenge of understanding RNA function at the global cellular level, as long as we embrace and nurture the serendipitous, viral, non-linear features of both science and RNA pathways.

Documented over the RNA journal's 20-year history, RNA has been — as Tom Cech and Joan Steitz quip— "trashing old rules" at an accelerating pace-that is, if we expect that Nature never does something, very likely she does, at least in certain cases. With many new genomes constantly being sequenced, we can expect many more surprises, as exemplified by the discovery of ever new, sometimes very rare riboswitch classes in bacterial genomes. New tools are also constantly being embraced by the community to be able to handle the intricacies of RNA pathways, for example, RNAseq, systems biology modeling, and single molecule observation. Studying the ubiquitous functions of RNA is extremely gratifying since RNA reaches back to the Origin of Life and reaches forward into a future of personalized medicine. So let us share this dream! 

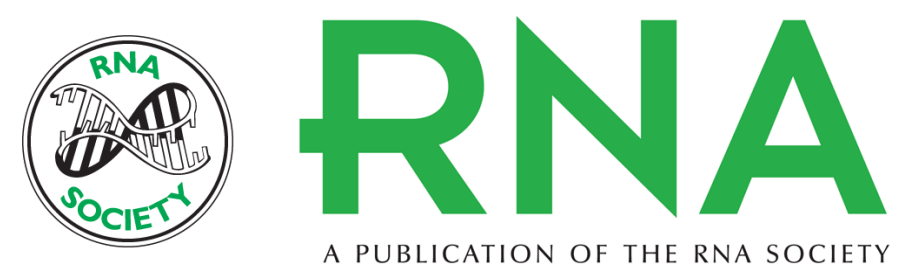

A PUBLICATION OF THE RNA SOCIETY

\section{Going viral: riding the RNA wave to discovery}

Nils G. Walter

RNA 2015 21: 756-757

Open Access Freely available online through the RNA Open Access option.

Creative This article, published in RNA, is available under a Creative Commons License Commons (Attribution-NonCommercial 4.0 International), as described at

License http://creativecommons.org/licenses/by-nc/4.0/.

Email Alerting Receive free email alerts when new articles cite this article - sign up in the box at the Service top right corner of the article or click here.

To subscribe to $R N A$ go to:

http://rnajournal.cshlp.org/subscriptions

(C) 2015 Walter; Published by Cold Spring Harbor Laboratory Press for the RNA Society 